\title{
Awareness on privacy settings in social networking sites among the undergraduates in Eastern University of Sri Lanka
}

\author{
J. Lavanya ${ }^{1}$, S. Santharooban ${ }^{2}$
}

\begin{abstract}
Use of Social networking sites (SNS) has grown rapidly over the past decades. Users occupy more time on social networking sites than other recreational activities. However, the tremendous use of Social Networking Sites is thereby prone to privacy concerns and risks. Therefore, a study was intended in an attempt to identify the reasons for using Social Networking Sites, examine the level of awareness of users on privacy settings, privacy policy and risk of avoiding privacy settings and to determine the training needs on the usage of Social Networking Sites among undergraduates of Eastern University, Sri Lanka. A cross-sectional survey design was employed to derive responses from a sample size of 391 undergraduates from the Eastern University, Sri Lanka selected through stratified random sampling. The present study revealed that the highest percentages of the undergraduates use SNS for Information sharing (93.07\%) and for Academic purposes (92\%), which was followed by Social interaction $(86.13 \%)$, Entertainment (85.33\%) and Self-Expression (81.87\%). It was noted that only $15 \%$ of the respondents have awareness about privacy policy at an excellent level. Moreover, around $20.06 \%$ and $24.13 \%$ of the undergraduates have marked their awareness level on privacy policy at a good and satisfactory level respectively. The overall median percentage for awareness about the privacy policy, settings, and associated risk is $58.33 \%, 66.7 \%$, and $66.7 \%$ respectively. Results revealed that municipality and faculty has a
\end{abstract}

1 Assistant Librarian, Library, Faculty of Health-Care Sciences, Eastern University, Sri Lanka

Email: 1.lavanya08@yahoo.com, (iD): https://orcid.org/0000-0002-8567-8202

2 Senior Assistant Librarian, Faculty of Health-Care Sciences, Eastern University, Sri Lanka

Email: santharooban@yahoo.com 
significant influence on awareness on privacy setting in SNS $(\mathrm{p}<0.05)$ and the urban has highest median awareness (70\%) than rural (58.6\%). The majority of the respondents confirmed that they required training on control cybercrimes (51.47\%) followed by SNS in higher education (48.8\%). It was recommended that university authorities should organize user education programmes to enhance knowledge of students on privacy settings in social networking sites as well as facilitators should assist students in incorporating them into their learning activities in a coherent way.

Keywords: Social Networking Sites, Awareness, Undergraduates, Privacy setting, Privacy concerns 


\section{Introduction}

The social networking sites (SNS) have been adopted as a part of everyone's in the technological era and its usage has grown exponentially and become a speedy means for effective communication. The world statistics have reported an average annual increase of $10 \%$ in the total number of users of social networking sites (Hawi \& Samaha, 2017). There are numerous social networking sites, such as Facebook, WhatsApp, Instagram, Twitter, LinkedIn, etc, which were emerged and changed the way people communicate, interact, investigate, and socialize.

Students in the younger generations are more dependent on Social Medias. It has been reported that majority of social media users are falling in student category (Lewis, 2009) and the students are using this to have a network or interact among friends and classmates especially on their study-related matters, discussion on national issues and often entertainment matters (Eke, Omekwu, \& Odoh, 2014). While the use of Social Media among students for their study purpose is highly appreciated, it has been found that this sometimes distract the students during classroom activities which result in negative impact on learning (Flad, 2010).

The social network sites offer a range of privacy settings on different aspects of information disclosure and messaging (Senthil Kumar, Saravanakumar \& Deepa, 2016). However, many users are not aware about the privacy settings and security concerns (Govani \& Pashley, 2007; Gross \& Acquisti, 2005). Every user of social network sites should be aware of the information privacy to avoid the negative repercussions. According to Beye et al.(2010) Information Privacy is an individual's claim to control the terms under which personal information, information identifiable to the individual is acquired, disclosed or used.

Lack of awareness on security and privacy setting will lead to detrimental effects such as cyber bullying, profile hacking, identity theft, photo morphing and social implications such as committing suicide, ethnic \& cultural issues. For instance, Cyber bullying has become a major issue among youth in the last couple of decades, as it allows its victims to post things in front of their peers and humiliate them. These issues left teenagers with deep mental scars, and have even led to teen suicides. There are many cases in Sri Lanka, for example, a teenager has committed suicide over a photo on Facebook ("Teenage suicide over a photo on FB," 2014). Another example is a youth has committed suicide in Puttalam area over heartbreak as a result of Facebook ("Facebook breakup results in suicide," 2016). There were similar cases even in Batticaloa in past years. This gives evidence that 
the deaths were the direct result of the victims' engagement with social media ("Sri Lanka mulls strategy to address adverse impact of social media on youth," 2014). In the 2018 March, the government of Sri Lanka forced shut down Facebook, WhatsApp, Instagram, and Viber in an attempt to quell ethnic strife in the country. However, after a few days, the ban on social networking sites was lifted and new communication regulations were implemented by the Sri Lankan government.

Nowadays, students have a lot of opportunities to use their smartphones to capture images and share photos and text to cyber communities through Facebook, Whatsapp etc not only with their friends but also with other cyber communities without considering security and privacy policy. It has become easier for malicious people to steal personal information on social networking sites and exploit them in various ways. The pervasive use of social media, especially among undergraduates is getting attention from researchers. Further, it was noted that the awareness of privacy settings in Social Networking Sites among the undergraduates in Eastern University has not been researched in detail by previous researchers. However, the awareness of privacy and security policy is questionable? Therefore, this study was intended to find the level of awareness on privacy and security concerns of Social Networking Sites among undergraduates of EUSL and to find the solutions to the matters arising with social networking sites.

\section{Research Objectives}

1. To identify the reasons for using Social Networking Sites

2. To examine the level of awareness of users on privacy setting, privacy policy and risk of avoiding privacy setting on Social Networking Sites

3. To determine the training needs on the usage of Social Networking Sites

\section{Literature Review}

Nowadays, privacy concerns of social networking sites are one of the most debated topics. Scholars have started to investigate the various aspects of social networking sites. This part contains a review of selected studies that have been carried out on various topics such as online social networking and privacy, the risk of social media, and awareness on security issues. Several studies had attempted to determine the implications of privacy concerns and awareness of privacy (Dinev \& Hart, 2005; Gross \& Acquisti, 2005; Goettke \& Christiana, 2007; Govani \& Pashley, 2007). 
Govani \& Pashley (2007) investigated student awareness of the privacy issues and the available privacy protection provided by Facebook. Their result revealed that the majority of the students were aware on negative effects caused by means of providing personnel information among university population but feel enjoyable in providing so. In contrast, Tow, Dell, \& Venable (2010) concluded that users were not aware of the issues or felt that the consequences are relatively low and they designed a preliminary theoretical model to explain the information disclosure phenomena. For example, Acquisti \& Gross (2006) highlighted in their study that the majority of Facebook members have knowledge on control the visibility and searchability of their profiles, but significant percentage of the students are unaware of those facilities provided by the SNS as well as only less amount of users change the default privacy settings.

There were several studies on SNS among undergraduates in universities too. Athukorala (2018) in her study on factors affecting the use of social media by university students at Wuhan University, China highlighted that the major contributing factors for the use of social media are privacy, convenience, and time spent. Based on this finding, she pointed out that social network providers should make necessary arrangements to protect user privacy as well as it is a prime duty of university authorities to incorporate media literacy education into academic curricula for both international students and faculty.

The openness on social networking sites seeks attention from strangers which may lead to online victimization of users. Abdulahi, Samadi, \& Gharleghi (2014) conducted a study on the negative effects of social network sites such as Facebook among Asia Pacific University scholars. They concluded that users are not aware of the risk associated by the openness. Weerasundera (2014) studied the impact of social media in Sri Lanka about issues and challenges in mental health and the author stated that suicides and other mental health problems propagated by social media are considered as the issues of global concerns and are not confined to Sri Lanka. Elci \& Seckin (2016) conducted a study on cyber bullying awareness among students and its association with gender, age, and internet usage at department of MIS in a government university in Turkey. 
They stated that cyber bullying not only affects student vigorously but also hurts their families too. The findings revealed that females have significantly less awareness than males. Access to the classified information may also lead to terrorism risks, financial risks and physical or sexual extortion (Gharibi \& Shaabi, 2012). Further, the researcher stated that major problems faced by the youngsters are identity theft, hacking and cyber bullying controversies. Discussion with youngsters revealed that most of them are 'unaware' and they do not want to change privacy settings offered by the social networking sites (Gangopadhyay \& Dhar, 2014).

Users can follow some precautionary practices to minimize the risks related to social networking sites. Kabay (2010) stated that most of the SNS provides opportunities for 'Blocking' the malicious people. Further the researcher highlighted that the users have been provided with the option to permanently block people on Facebook. Bae \& Kim (2010) indicated that the user have the authority to control the privacy setting in order to maintain a higher level of privacy. In addition, the authors noted the importance of developing a privacy policy to protect information by blocking strangers from visibility and searchability of personal information.

Fong, Anwar, \& Zhao ( 2009) proposed a privacy preservation model for social networking sites. They analyzed the mechanism of controlling access in Facebook. Danezis (2009) introduced a machine learning approach that was used to automatically find the privacy settings of users and give a readymade privacy policy package to the users. This approach was targeted to assist the end-users to control access from unwanted contacts.

Fang, Kim, LeFevre, \& Tami (2010) designed a privacy recommendation wizard based on user inputs to help users classify their friend list into sublists. The wizard helped to allow the friends in their sub-list to see their personal information and to deny them access to this information.

According to the literature, several studies have been conducted about awareness on Social Networking Sites, privacy policies, the role of social networking sites in higher education among students and adults in Sri Lankan context and internationally. The above studies helped in building a 
framework to explore the usage, awareness and training needs on SNS among students. Furthermore, the research on privacy concerns, especially among undergraduates is minimal and these kinds of researches have not been extensively covered by previous researchers at Eastern University too. Therefore, this research necessitates the study of the awareness level of EUSL undergraduates in order to fill the gaps in the current literature.

\section{Methodology}

This study is a cross-sectional study. Four thousand six hundred and thirty four (4634) students of six faculties including Agriculture, Arts and culture, Commerce and Management, Health-Care Sciences, and Science and Technology of the Eastern University, Sri Lanka were the population of this study. The sample size was calculated using Krejcie \& Morgan (1970) formula. According to the calculation, the final sample size was 391 with a $10 \%$ non-response rate. This has been proportionately divided into faculties and then into gender. Stratified random sampling was employed to draw the respondents as it involves division of a population into smaller sub-groups and the gender is considered as strata. Self-administered questionnaires were used to collect information from the randomly selected undergraduates. The response rate was $95 \%$. Descriptive statistics have been performed in order to identify the reasons for using Social Networking Sites and the training needs on the usage of Social Networking Sites. The awareness was measured using variables such as awareness on privacy policy, privacy setting and risk of avoiding privacy setting on Social Networking Sites. The awareness of privacy policy included the statements on terms of use and privacy policy of SNS, visibility of personal profile information when ignore privacy settings, and sharing of personal information by SNS for marketing purpose. The awareness of privacy setting included the statements on preventing others from accessing personal information, blocking unwanted users and ability to change privacy settings. The awareness on the risk of avoiding privacy settings included the statements on profile hacking and photo morphing, cyber-bullying and identity theft, and social implication caused by SNS. These statements were checked using five-point Likert scale (ranging from 1 $=$ Strongly Disagree; $2=$ Disagree; $3=$ Neutral; $4=$ Agree to $5=$ Strongly Agree). Further, non-parametric tests such as the Man-Whitney U test and Kruskal-Wallis test were performed to compare the means. 
A pilot study was conducted among the selected twenty students to test and revise the study instrument and the reliability was tested using Cronbach alpha test. The average Cronbach alpha for the questionnaire is 0.8 , which is acceptable for the tool. The students who contributed to the pilot study were excluded from the data collection. The descriptive statistics were used to analyze the data with the aid of SPSS software. The significance test was done with $95 \%$ of the confidence interval. Ethical approval was obtained from the Ethics Review Committee of Faculty of Health-Care Sciences, Eastern University, Sri Lanka (E/2018/76).

\section{Results and Discussion}

\section{Profile of respondents}

The gender-wise distribution of undergraduates participated in the study was recorded. It was observed that $72.9 \%$ were females and $21.9 \%$ were male. The study stated that $61.4 \%$ and $38.6 \%$ of the undergraduates are from rural and urban municipalities respectively. The faculty wise numbers of respondents are given below (Table 1). Since the undergraduate population in the faculty of Arts and Culture is large, around 50\% of respondents come from this faculty according to proportionate sample size allocation.

Table 1. Faculty wise distribution of respondents

\begin{tabular}{ll}
\hline Faculty & Frequency \\
\hline Agriculture & $24(6.4 \%)$ \\
Arts and culture & $188(50.1 \%)$ \\
Commerce and Management & $57(15.2 \%)$ \\
& \\
Heath care Sciences & $45(12 \%)$ \\
Science & $48(12.8 \%)$ \\
Technology & $13(3.5 \%)$ \\
Total & $\mathbf{3 7 5 ( 1 0 0 \% )}$ \\
\hline
\end{tabular}

\section{Use of Social Network Sites}

As per the usage, the WhatsApp dominates other social media among undergraduates who come from rural and urban and which was followed by 
Facebook (Table 2). This increasing popularity of WhatsApp over Facebook has been reported by other studies too. Raj, Bhattacherjee, \& Mukherjee (2018) stated that although Facebook holds the most dominant spot in many surveys, WhatsApp topped the ranking in their study conducted among school students of West Bengal, India. However, very few have an account on LinkedIn (8.53\%), ResearchGate (4\%) and Academia (2.67\%). Lavanya \& Santharooban (2018) pointed out that only few students have an account on ResearchGate (5.4\% of males, $1 \%$ of females) and Academia. Edu (3.6\% of males and $3.1 \%$ of females). One of the reasons may be due to lack of awareness about these sites among the students and another reason is the ResearchGate requires the institutional email to set up an account and many universities in Sri Lanka are not providing institutional email for students.

Table 2. Social Networking Sites and Municipality

\begin{tabular}{lcr}
\hline \multirow{2}{*}{ SNS } & \multicolumn{2}{c}{ Municipality } \\
\cline { 2 - 3 } & $\begin{array}{c}\text { Rural } \\
\text { (\%) }\end{array}$ & \multicolumn{1}{c}{ Urban (\%) } \\
\hline Facebook & 63.96 & 64.52 \\
Instagram & 14.21 & 31.45 \\
Twitter & 11.68 & 16.13 \\
WhatsApp & 96.95 & 95.97 \\
Viber & 57.36 & 58.87 \\
Google+ & 52.79 & 48.39 \\
IMO & 50.25 & 35.48 \\
\hline
\end{tabular}

The study analyzed the relationship between types of social network usage and the gender and found that no social networking sites associated with gender ( $p>0.05$, for chi-squared test), i.e. social networking sites are equally preferred by each gender. As indicated in the table below 56.2\% and $96.9 \%$ of the females were using Facebook and WhatsApp respectively (Table 3). Meanwhile, $84.7 \%$ and $94.9 \%$ of the males have used Facebook and WhatsApp respectively. 
Table 3. Social Networking Sites and Gender

\begin{tabular}{lrr}
\hline \multirow{2}{*}{ SNS } & \multicolumn{2}{c}{ Gender } \\
\cline { 2 - 3 } Facebook & M (\%) & F (\%) \\
\hline Instagram & 84.69 & 56.27 \\
Twitter & 42.86 & 12.17 \\
WhatsApp & 25.51 & 9.13 \\
Viber & 94.90 & 96.96 \\
Google+ & 66.33 & 54.37 \\
IMO & 57.14 & 47.53 \\
Academia & 48.98 & 42.21 \\
LinkedIn & 5.10 & 1.90 \\
Research Gate & 15.31 & 6.46 \\
\hline
\end{tabular}

Information sharing was the traditional reason for using SNS from its inception. Nowadays, social networking sites create platforms for students to discuss and share ideas on various matters, thereby educate themselves on such issues. As such, the present study revealed that the highest percentages of the undergraduates use SNS for Information sharing (93.07\%) and for Academic purposes $(92 \%)$, which were followed by Social interaction (86.13\%), Entertainment (85.33\%) and Self-Expression (81.87\%).

Whiting \& Williams (2013) identified 10 purposes of using social media such as social interaction, information seeking, time passing, entertaining, relaxing, communicatory utility, convenience utility, expressing opinion, Sharing of information, and surveillance. The study also revealed that the reasons for using SNS such as information sharing, social interaction, entertainment, and self-expression had significant but small association (according to Cramer V test) with gender (Table 4). As such, the above reasons are associated with males than females. A study on Gender differences in social media usage and academic performance among the students of the University of Sharjah showed that males were highly attracted by social networks than females (49.6\%) and (32\%), respectively (Alnjadat, Hmaidi, Samha, Kilani, \& Hasswan, 2019). Similarly, Manjunatha (2013) pointed out that male students use SNS more than females. Among the total users, $71 \%$ of the users are males and the rest of the percentage is 
females. Moreover, it was noted that more males used SNS for selfexpression than females which gives evidence that boys are more likely to utilize social networking sites for self- expression than girls.

Table 4. Cross-tabulation between Reasons for using SNS and Gender

\begin{tabular}{|c|c|c|c|c|c|}
\hline Reasons & $\begin{array}{c}\text { Male } \\
(\%)\end{array}$ & $\begin{array}{c}\text { Female } \\
(\%)\end{array}$ & $\chi^{2}(\mathbf{d f}=1)$ & P-value & Cramer V \\
\hline $\begin{array}{l}\text { Information } \\
\text { sharing }\end{array}$ & 97.96 & 92.02 & 4.23 & $0.040^{*}$ & 0.108 \\
\hline $\begin{array}{l}\text { Academic } \\
\text { activity }\end{array}$ & 94.90 & 92.02 & 0.89 & 0.350 & \\
\hline $\begin{array}{l}\text { Social } \\
\text { interaction }\end{array}$ & 95.93 & 82.89 & 10.33 & $0.001 * *$ & 0.169 \\
\hline Entertainment & 96.94 & 81.75 & 13.58 & $0.000^{* *}$ & 0.194 \\
\hline $\begin{array}{l}\text { Self- } \\
\text { Expression }\end{array}$ & 96.94 & 76.81 & 19.84 & $0.000^{* *}$ & 0.234 \\
\hline
\end{tabular}

Awareness about the privacy policy, settings and associated risk

The awareness was considered in three aspects: awareness about the privacy policy of SNS, awareness about setting privacy, and awareness about the risk of ignoring privacy settings. Overall awareness about the privacy policy, settings, and associated risk were categorized as $0-49 \%$ - Below average; 50 69\% - Satisfactory; 70-89\% - Good and Excellent 90-100\%.

Awareness about privacy policy was measured by asking statements like "I am aware on terms of use and privacy policy of SNS", "I am aware that if I haven't changed my privacy setting, all members of same network can see my profile" and "I am aware that SNS can share my information with people or organizations outside of SNS for marketing purpose as their privacy policy". It was noted that only $15.5 \%$ of the respondents have awareness about privacy policy at an excellent level (Figure1). Therefore, Social networking should be incorporated into the information policy and user education. Haraty \& Massalkhy (2013) pointed out that users reveal personal information because of unawareness and the rigidity of the privacy policies. However, users accept the privacy policy and granting their ownership of data to social network administrators knowingly or unknowingly. 
The figure 1 represents the awareness level of privacy settings among undergraduates. In order to identify the awareness of privacy settings, the data have been gathered under categories such as the prevention of other users from seeing personal information, blocking unwanted users in SNS as well as the abilities of the user to change privacy settings.

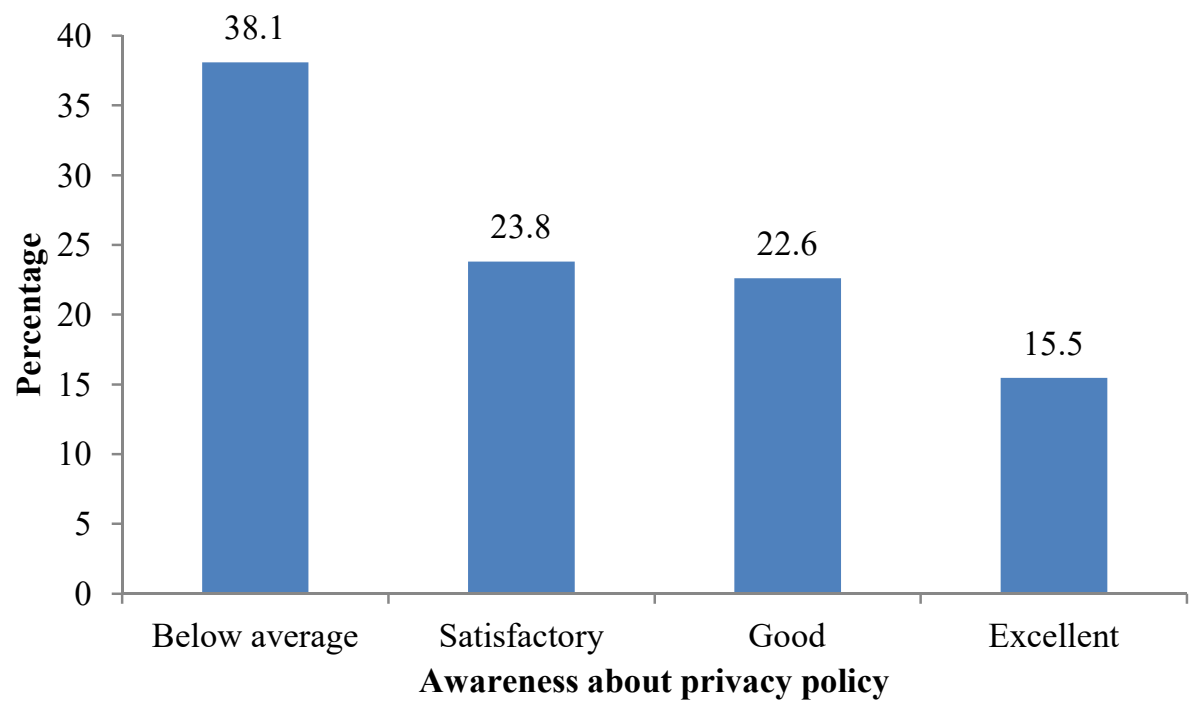

Figure 1. Awareness about the privacy policy of SNS

The results revealed that $20.1 \%$ and $24.1 \%$ of the undergraduates have marked their awareness level at privacy setting at a good and satisfactory level respectively (Figure 2). Privacy settings would help users to control over the profile view and personal information. The privacy setting varies among social networking sites. The lack of awareness on privacy settings leads to negative consequences. This seems that the university authorities should take more concern in enhancing the level of awareness regarding privacy settings in SNS. Gross \& Acquisti (2005) analyzed the Facebook profiles of more than 4000 students and found that only a small percentage had changed the default privacy settings. 


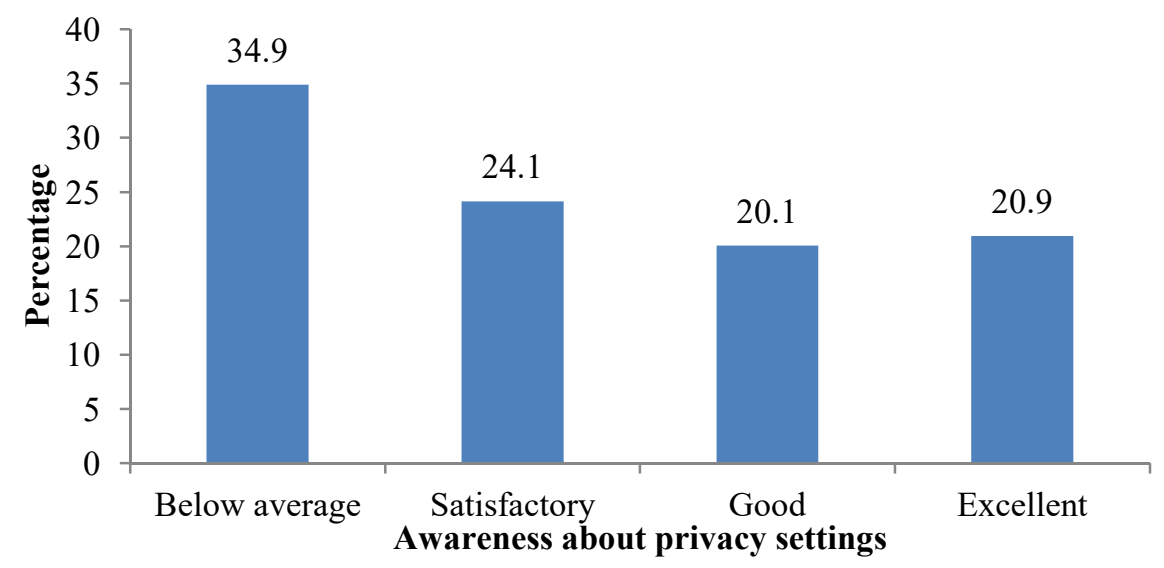

Figure 2. Awareness of privacy setting

Figure 3 indicated the awareness of the risk of neglecting privacy settings. It was measured by getting answers for the following criteria viz awareness on profile hacking, photo morphing, cyber-bullying, identity theft and social implication caused by SNS such as suicide, ethnic \&cultural issues. It was noted that less than $20 \%$ of the students have awareness on adverse effects caused by ignoring privacy setting at good and excellent level. It is stressed that the users should have more awareness to protect themselves from organized cybercrime, identity theft, scams, and malware attacks. These challenges should be addressed in a proper way to avoid potential loss of private and personal information. Gross \& Acquisti (2005) highlighted possible drawbacks on ignoring privacy settings.

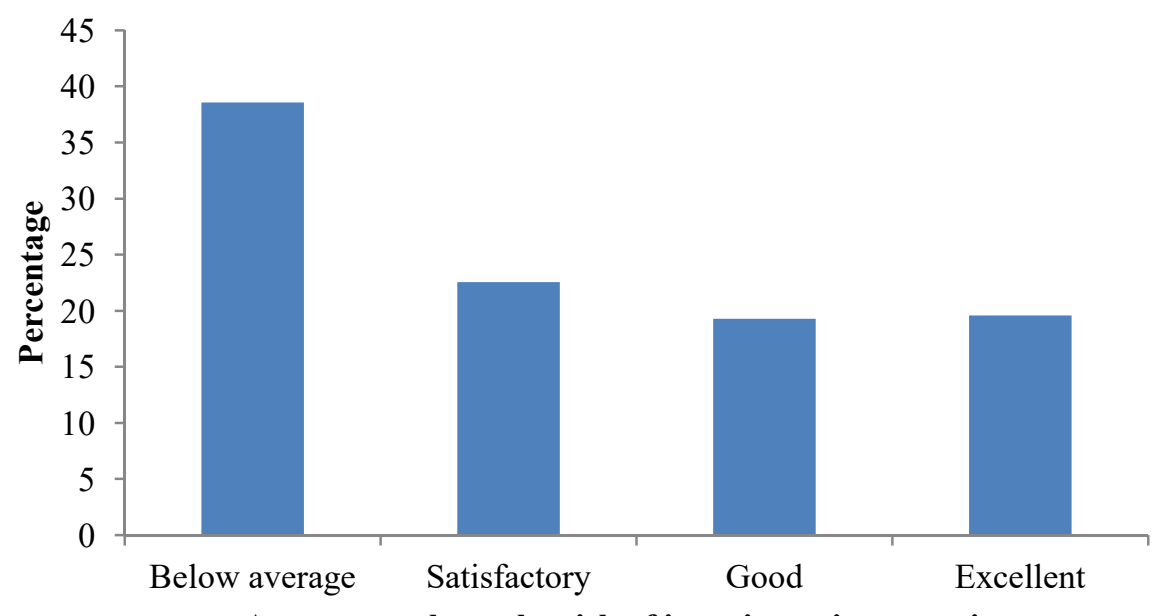

Figure 3. Awareness of the risk of ignoring privacy settings 
The overall median percentage for awareness about the privacy policy, settings, and associated risk is $58.33 \%, 66.7 \%$, and $66.7 \%$ respectively. All three types of awareness do not follow a normal distribution as per the Kolmogorov-Smirnov test and Shapiro-Wilk test $(\mathrm{p}<0.05)$ at a 95\% confidence interval. Therefore non-parametric tests such as the ManWhitney $U$ test and Kruskal-Wallis test were performed to compare the means. Gender does not influence any of the three types of awareness $(\mathrm{p}>0.05)$.

The municipality has significant influence only on awareness on privacy settings in SNS $(\mathrm{U}=16,109.5, \mathrm{p}=0.013)$ and the urban has the highest median awareness $(70 \%)$ than rural $(58.6 \%)$. The faculty also has an influence only on awareness on privacy settings in SNS (test statistic $=26.13, \mathrm{df}=5$, $\mathrm{p}=0.000$ ). The pairwise comparison (Table 5) shows that the student from the faculty of Arts and Culture has the lowest median awareness than other faculties $(\mathrm{p}<0.05)$ and there is no significant difference among other faculties $(\mathrm{p}>0.05)$.

Table 5. The pairwise comparison of faculties about awareness on SNS

\begin{tabular}{ll}
\hline \multicolumn{1}{c}{ Faculty } & $\begin{array}{l}\text { Median } \\
\text { (\%) }\end{array}$ \\
\hline Faculty of Health-Care Sciences & 75 \\
Faculty of Science & 75 \\
Faculty of Agriculture & 70.8 \\
Faculty of Commerce and Management & 66.7 \\
Faculty of Technology & 66.7 \\
Faculty of Arts and Culture & 58.3 \\
\hline
\end{tabular}

\section{Training Needs in SNS}

The training needs in terms of Social Networking Sites were identified. The majority of the respondents confirmed that they required training on Control cybercrimes $(51.47 \%)$ followed by SNS in higher education (48.8\%). 
Table 6. Training Needs in SNS

\begin{tabular}{lll}
\hline Training needs & Sum & Percentage (\%) \\
\hline Security \& privacy setting & 148.00 & 39.4 \\
Control cyber crimes & 193.00 & 51.47 \\
Overcome SNS Addiction & 149.00 & 39.73 \\
SNS in higher education & 183.00 & 48.80 \\
\hline
\end{tabular}

$79.17 \%$ of respondents from the faculty of Agriculture stated that they need training on how to overcome SNS addiction. Around $69.23 \%$ and $62.5 \%$ of the students from the Faculty of Technology and Agriculture required training on control cybercrime respectively.

Table 7. Faculty wise distribution of Training Needs in SNS

\begin{tabular}{lccrccc}
\hline $\begin{array}{l}\text { Training } \\
\text { needs }\end{array}$ & $\begin{array}{c}\text { Agricu } \\
\text { lture }\end{array}$ & Arts & Com\&Mgt & FHCS & Science & Technology \\
\hline $\begin{array}{l}\text { Security \& } \\
\text { privacy setting }\end{array}$ & 41.67 & 35.11 & 42.11 & 35.56 & 54.17 & 46.15 \\
$\begin{array}{l}\text { Control cyber } \\
\text { crimes }\end{array}$ & 62.50 & 51.06 & 42.11 & 40.00 & 64.58 & 69.23 \\
$\begin{array}{l}\text { Overcome SNS } \\
\text { Addiction }\end{array}$ & 79.17 & 40.96 & 22.81 & 26.67 & 50.00 & 30.77 \\
$\begin{array}{l}\text { SNS in higher } \\
\text { education }\end{array}$ & 50.00 & 55.32 & 29.82 & 42.22 & 50.00 & 53.85 \\
\hline
\end{tabular}

\section{Conclusion and Recommendations}

The significant rise in the involvement of undergraduates on social networking sites (SNSs) has led to considerable concern about awareness on privacy settings, policy, and associated risk. The study revealed that WhatsApp has become the most preferred social network site among undergraduates than Facebook (Male- 94.9\% \& Female- 96.96\%). However, scholarly networking sites such as ResearchGate and Academia are not widely used by undergraduates. Therefore, undergraduates should be encouraged to have an active account on academic SNS. This would help them to access authentic documents written by scholars. The present study revealed that the highest percentage of the undergraduates uses SNS for information sharing (93.07\%) 
and for academic purposes (92\%), which were followed by social interaction (86.13\%), entertainment $(85.33 \%)$ and self-expression $(81.87 \%)$. Even though the use of social networking sites is increasing day by day, the users are not aware of the risks associated with neglecting privacy concerns.

The overall median percentage for awareness about the privacy policy, settings, and associated risk is $58.33 \%, 66.7 \%$, and $66.7 \%$ respectively. It gives evidence that the students' privacy concerns in the social networking sites are very feeble and the users should make the appropriate changes to privacy settings of SNS. In addition, the faculty has an influence on awareness on privacy settings in SNS (test statistic $=26.13, \mathrm{df}=5, \mathrm{p}=0.000$ ). The pairwise comparison showed that the student from the faculty of Arts and Culture has the lowest median awareness than other faculties $(\mathrm{p}<0.05)$.

Most of the students preferred to have training on Control cybercrimes $(51.47 \%)$ and SNS in higher education (48.8\%). Drawn from the findings, it was recommended that university authorities should organize adequate workshops on social network sites and related privacy issues to the undergraduates. This would help them to use SNS effectively as well as get rid of the issues stimulated by cybercrimes. Teaching professionals are encouraged to modify the curriculum to integrate social media into learning approaches as more students required training on SNS in higher education.

\section{References}

Abdulahi, A., Samadi, B., \& Gharleghi, B. (2014). A Study on the Negative Effects of Social Networking Sites Such as Facebook among Asia Pacific University Scholars in Malaysia. International Journal of Business and Social Science, 5(10). retrieved from www.ijbssnet.com

Acquisti, A., \& Gross, R. (2006). Imagined Communities: Awareness, Information Sharing, and Privacy on the Facebook. International Workshop on Privacy Enhancing Technologies (PET), 36-58. Berlin,Heidelberg: Springer. 
Alnjadat, R., Hmaidi, M. M., Samha, T. E., Kilani, M., \& Hasswan, A. M. (2019). Gender variations in social media usage and academic performance among the students of University of Sharjah. Journal of Taibah University Medical Sciences, 14(4), 390-394. https://doi.org/10.1016/j.jtumed.2019 .05. 002

Athukorala, A. W. V. (2018). Factors Affecting Use of Social Media by University Students: A study at Wuhan University of China. Journal of the University Librarians Association of Sri Lanka, 21(2), 44-72. https:// doi.org/10.4038/jula.v21i2.7917

Bae, S. H., \& Kim, J. (2010). Development of Personal Information Protection Model using a Mobile Agent. Journal of Information Processing Systems, 6(2), 185-196. https://doi.org/10.3745/JIPS.2010.6.2.185

Beye, M., Jeckmans, A., Erkin, Z., Hartel, P., Lagendijk, R., \& Tang, Q. (2010). Literature Overview - Privacy in Online Social Networks. https:// doi.org/10.1007/978-1-4471-4051-1

Danezis, G. (2009). Inferring privacy policies for social networking services. Proceedings of the ACM Conference on Computer and Communications Security, 5-10. https://doi.org/10.1145/1654988.1654991

Dinev, T., \& Hart, P. (2005). Internet Privacy Concerns and Social Awareness as Determinants of Intention to Transact. International Journal of Electronic Commerce, 10(2), 7-29. https://doi.org/10.2753/JEC10864415100201

Eke, H. N., Omekwu, C. O., \& Odoh, J. N. (2014). The Use of Social Networking Sites among the Undergraduate Students of University of Nigeria, Nsukka. Library Philosophy and Practice (e-Journal) retrieved fromhttp:// digitalcommons.unl.edu/libphilprac\%5Cnhttp:// digitalcommons. unl.edu/libp hilprac/1195

Elci, A., \& Seckin, Z. (2016). Cyberbullying Awareness for Mitigating Consequences in Higher Education. Journal of Interpersonal Violence. https://doi.org/10.1177/0886260516646095 
Facebook breakup results in suicide. (2016, April 13). Hiru News. Retrieved from http://www.hirunews.lk/130776/facebook-breakup-results-in-suicidephotos

Fang, L., Kim, H., LeFevre, K., \& Tami, A. (2010). A privacy recommendation wizard for users of social networking sites. Proceedings of the 17th ACM Conference on Computer and Communications Security - CCS '10, (January 2010), 630-632. https://doi.org/10.1145/1866307.1866378

Flad, K. (2010). The Influence of Social Networking Participation on Student Academic Performance Across Gender Lines.(Counselor Education Master's Theses). The College at Brockport.

Fong, P. W. L., Anwar, M., \& Zhao, Z. (2009). A privacy preservation model for facebook-style social network systems. European Symposium on Research in Computer Security, 303-320. https://doi.org/10.1007/978-3-64204444-1_19

Gangopadhyay, S., \& Dhar, D. (2014). Social networking sites and privacy issues concerning youths. Global Media Journal-Indian Edition, 5(1).

Gharibi, W., \& Shaabi, M. (2012). Cyber threats in social networking websites. International Journal of Distributed and Parallel Systems (IJDPS), 3(1), 119-126. https://doi.org/10.5121/ijdps.2012.3109

Goettke, R., \& Christiana, J. (2007). Privacy and Online Social Networking Websites. Computer Science 199r: Special Topics in Computer Science Computation and Society: Privacy and Technology.

Govani, T., \& Pashley, H. (2007). Student awareness of the privacy implications when using Facebook (Carnegie Melon University). https://doi.org/ 10.1080/09539960500334087

Gross, R., \& Acquisti, A. (2005). Information Revelation and Privacy in Online Social Networks (The Facebook case). Human Factors, 71-80. https://doi.org/ 10.1145/1102199.1102214 
Haraty, R. A., \& Massalkhy, S. (2013). UPP +: A Flexible User Privacy Policy for Social Networking Services. In Security and Privacy Preserving in Social Networks. 139-155. https://doi.org/10.1007/978-3-7091-0894-9

Hawi, N. S., \& Samaha, M. (2017). The Relations Among Social Media Addiction, Self-Esteem, and Life Satisfaction in University Students. Social Science Computer Review, 35(5), 576-586. https://doi.org/10.1177/08 94439 316660340

Kabay, M. E. (2010). Privacy issues in social-networking sites. Retrieved October 20, 2018, from NetworkWorld website: https://www.net workworld.com/article/2237560/collaboration-social/privacy-issues-in social - networking-sites.html

Krejcie, R. V, \& Morgan, D. W. (1970). Determining sample size for research activities. Educational and Psychological Measurement, 30, 607610. https://doi.org/https://doi.org/10.1177/001316447003000308

Lavanya, J., \& Santharooban, S. (2018). Usage of Online Resources by the Undergraduates Attached to the Faculty of Agriculture, Eastern University, Sri Lanka. Journal of the University Librarians Association of Sri Lanka, 21(2), 89-105. https://doi.org/10.4038/jula.v21i2.7919

Lewis, B. K. (2009). Social Media and Strategic Communication: Attitudes and Perceptions Among Collage Students. (Doctorl Dissertation). Oklahoma State University Stillwater, Oklahoma. https://doi.org/10. 1017/CBO9781 107415324.004

Manjunatha, S. (2013). The Usage of Social Networking sites Among the College Students in India. International Research Journal of Social Sciences, 2(5), 15-21. Retrieved from www.isca.in

Raj, M., Bhattacherjee, S., \& Mukherjee, A. (2018). Usage of Online Social Networking Sites among School Students of Siliguri, West Bengal, India. Indian Journal of Psychological Medicine, 40(5), 452-457. https://doi .org/10.4103/IJPSYM.IJPSYM_70_18 
Senthil Kumar, N., Saravanakumar, K., \& Deepa, K. (2016). On Privacy and Security in Social Media - A Comprehensive Study. Physics Procedia, 78, 114-119. https://doi.org/10.1016/j.procs.2016.02.019

Sri Lanka mulls strategy to address adverse impact of social media on youth. (2014, February 22). Colombo Page. Retrieved from http://www. colombopage.com/archive_14A/Feb22_1393087318CH.php

Teenage suicide over photo on FB. (2014, February 6). Daily Mirror. Retrieved from http://www.dailymirror.lk/42706/teenage-suicide-over-photo -on-facebook

Tow, W. N. F. H., Dell, P., \& Venable, J. (2010). Understanding information disclosure behaviour in Australian facebook users. Journal of Information Technology, 25(2), 126-136. https://doi.org/10.1057/jit.2010.18

Weerasundera, R. (2014). The impact of social media in Sri Lanka: issues and challenges in mental health. Sri Lanka Journal of Psychiatry, 5(1), 1-2. https://doi.org/10.4038/sljpsyc.v5i1.7049

Whiting, A., \& Williams, D. (2013). Why people use social media: a uses and gratifications approach. Qualitative Market Research: An International Journal, 16(4), 362-369. https://doi.org/10.1108/QMR-06-2013-0041 